\title{
Diagnosing the Securitisation of Immigration at the EU Level: A New Method for Stronger Empirical Claims
}

\begin{abstract}
Has immigration been securitized at the EU level? The question has been hotly discussed, but no consensus has been reached. The present paper claims that two shortcomings - one methodological, one theoretical - in the empirical conduct of securitization theory (ST) have provoked this lack of consensus. Taking this situation as an opportunity, we introduce a quantitative method that addresses these two shortcomings, therefore helping to reach a stronger claim on the securitization of immigration at the EU level. By measuring the intensity of the security framing in EU legislation on immigration, our method helps avoiding simplistic binary statements of (non-)securitization and encourages the scholar to acknowledge the complex, multifaceted reality of vast political fields. Our results contribute to accredit the thesis according to which immigration has been securitized at the EU level, but nuance it by demonstrating a significant variation between the various subfields of the policy (e.g. asylum, legal immigration).
\end{abstract}

In an "age of migration" (Castles and Miller, 2009), migration and immigration policies are increasingly central and should be thoroughly scrutinized from various angles. Immigration policies provoke highly polemical discussions, mainly because of visible "hard security" elements such as detention camps or fortified walls. In this regard, throughout the 2000s and until now, a question has recurrently been raised by scholars working at the cross of European studies and security studies: has immigration been securitized at the EU level, that is, has the immigration phenomenon successfully been framed as a threat and transformed by EU authorities in a security issue calling for policies of exception? This question, which makes sense within the theoretical framework of Securitization Theory (ST), is of prime importance given the potential ethical problems that a securitized migration policy may create. Drawing on several schools of thought (e.g. "speech act" theory, framing analysis, etc.), ST studies the dynamics through which political actors transform, more or less consciously, a social issue into a security issue; the consequences of such processes are also analysed.

ST scholars present an impressive record of articles devoted to the sole question of the securitization of immigration at the EU level. Despite of this profusion however, we believe that ST scholars have not yet clearly established if immigration has indeed been securitized at the EU level. Contradictory but equally vigorous claims have indeed been made on the presence/absence of securitization in the field of EU immigration policies in the last decades.

One the one side, people like Huysmans (2000), Bigo (2002), Sasse (2005), Karyotis (2007) or Balzacq (2008) have all concluded that EU immigration policies have undoubtedly been securitized. In 2000, Huysmans famously claimed that European integration has led to "the securitization of immigrants, asylum-seekers, and refugees in the EU" (Huysmans, 2000: 753). This claim, indebted to Bigo's 1998 assertion that immigration had been framed as a threat by EU actors (Bigo, 1998 translated in Bigo, 2002), paved the way for ST studies of EU immigration policy. He argued that not only had the "Europeanization of migration policy [...] directly securitized migration", but also that it "indirectly sustained the securitization of migration" (Huysmans, 2000: 770). This view has been endorsed several times since then. In 2004, Buonfino noted that "immigration has turned into one of the greatest security concerns of 21 st century Europe", and claimed that "immigration as a threat and a security concern has become the hegemonic discourse type in government policy" (Buonfino, 2004: 23-24). In 2007, Karyotis reinforced this view according to which EU immigration policy is the successful result of a securitizing move which has gained efficiency after the $9 / 11$ events (Karyotis, 2007). 
On the other side, scholars like Boswell and Neal have explicitly refuted these conclusions. Boswell, for example, claimed that "migration control policies in Europe do not appear to have become securitized" (Boswell, 2007: 606), and that "by and large, there is remarkably little evidence of attempts to securitize migration in Europe" (Boswell, 2007: 590). She acknowledged that attempts to securitize immigration have been made on several occasions, but observed their failure and insisted that alternative framings (business, human rights, etc.) are equally influential. Neal followed this research agenda and suggested that EU immigration policies should be analysed in terms of risk management rather than in terms of security struggle strictly speaking (Neal, 2009). A similar view has been adopted by Van Munster in his book Securitizing immigration: the politics of risk in the EU (Van Munster, 2009). Acknowledging this, Huysmans published a new paper on the topic in 2008, wherein he accepted that no consensus could be reached on the hypothetical securitization of immigration at the EU level. To us, this "balanced" conclusion reflects the confusion that reigns on the issue of the securitization of immigration at the EU level; it cannot count as a definitive consensus.

Since a theory is best judged with regards to its ability to produce consistent empirical results, this divergence "cannot only be celebrated as 'diversity"' (Stritzel, 2007: 359). In this context, the present paper contributes to producing a more objective answer to the question of the securitization of immigration at the EU level; it does so by identifying the shortcomings of ST that provoked this "diversity", and by putting forward a quantitative method that aims at correcting these shortcomings, thereby helping to confirm/refute a diagnosis of securitization. The article is therefore divided into three sections. In a first section we make the claim that the divergence on the issue of the securitization of EU immigration policies comes from both methodological and theoretical imperfections. More precisely, we argue that the methodological procedures usually followed in empirical ST cast doubt on their conclusions, and that securitization scholars ought to consider the intensity of securitization moves. In a second section, we present our method, expose its position and ambition within ST, and explain how it helps correcting these two problems; we detail how we put it at play in the case of EU immigration policy. Based on a tailored use of the LIWC software, our method automatically detects the saliency of security narratives in documents. In a third section, we present and discuss the results produced by our method, which tend to accredit the thesis of securitization - although in a nuanced way.

\section{The securitization of immigration at the EU level: Explaining the lack of consensus}

Why do existing studies of the securitization of migration policies at the EU level provide so different results? We suggest that two shortcomings of applied ST - one methodological, one theoretical - are responsible for this discrepancy.

\section{a) Method: The problem with evaluative procedures}

We argue that a widely shared lack of methodological commitment in the practice of ST have undermined the conclusions reached by its scholars on EU migration policies. Securitization studies are based on a well-thought and reflexive theoretical framework that has repeatedly been refined since Waever, Buzan and De Wilde's original propositions (1998). Our intention is not to criticize this background. Rather, our point is that empirical securitization case-studies do not enjoy the same strength that theoretical investigations, and that ST analyses of EU immigration policy are particularly illustrative of this problem. There are very few strictly methodological ST contributions, and the methodological choices and tools that bring about the conclusions seldom appear in empirical ST papers. This practice corresponds to the "evaluative procedures" denounced by Morse and colleagues (in opposition to "constructive procedures"), where a priori criteria of internal validity and reliability are abandoned in profit of ex post subjective impressions on "the overall significance, relevance, impact, and utility of completed research" (Morse et al., 2002: 14). Methods are indeed the Achilles' heel of securitization studies, casting doubt on their conclusions. Balzacq and Leonard already noticed that 
the "results of a large number of empirical studies conducted in the last decade are not always commensurate with the theoretical premises of securitization" (Balzacq and Leonard, 2011: 3). We do not claim that all conclusions of empirical securitization studies are flawed; we do, however, observe that securitization scholars are often tempted (not) to detect securitization where they want, and not where it actually is (not) - an inclination which might be curved down by a real commitment to transparent and robust methods. Balzacq recognized that "it is generally assumed that the way in which securitization occurs is essentially an empirical question, but, paradoxically, there has been little discussion on methods" (Balzacq, 2011c: 31); he therefore urged scholars to address this problem: "the main task facing students of securitization is not to add to the already long list of arguments and conjectures but instead to unpack and re-present these diverse approaches into a coherent set of assumptions guiding empirical research" (Balzacq, 2011a: xiv). In line with this demand, Salter's and Mutlu's recent book (2012) proves that scholars in critical security studies in general have come to recognise this gap and are willing to address it. However, it is remarkable that contributions to this volume offer general reflexions but no clear-cut instructions on how to practically implement these considerations.

To our knowledge, only Bourbeau (2011), Vultee (2011), and Karyotis and Patrikios (2010) have produced (very different) empirical ST studies wherein methods are exposed in a very clear and detailed way. All three, interestingly, operate at a distance from purely qualitative approaches to include some sort of measurement (which does not make them quantitative papers, however). Each of these three studies brought about important insights on immigration policies thanks to a rigorous and transparent method, but none has focused on migration at the EU level, and as we will see none has overcome the binary logic that make empirical ST over-simplify reality.

In this general context, we are forced to observe that no paper on the securitization of immigration at the EU level follows a clear-cut method (whichever it might be) or at least exposes it to the reader in a transparent fashion. The methodological issue in the specific case of EU immigration policy has two intermingled components. First, the documents or events upon which the analysis is made seem to be chosen rather than rigorously selected according to an openly defended selection or sampling principle. To know why researcher A studies texts $\mathrm{W}$ and $\mathrm{X}$, whereas the researcher $\mathrm{B}$ focuses on texts $\mathrm{Y}$ and $\mathrm{Z}$, with both $\mathrm{A}$ and $\mathrm{B}$ aiming to detect securitization moves of immigration at the EU level, has so far been impossible for the reader. Sampling preoccupations have indeed been absent of ST studies of EU immigration policy, except to some extent in Huysmans (2008). ${ }^{1}$ Second, none of the papers on the topic explains how the chosen documents/events have been analysed. In other words, the reader cannot be assured that the writer has not selected (or ignored) what suited him/her best in the texts or course of events.

\section{b) Theory: Acknowledging complexity}

The second explanation for the diverging conclusions reached on the securitisation of immigration at the EU level relates to the loose nature of the question to which many ST researchers dealing with EU migration policy strive to answer: "has migration been securitized at the EU level?". This question fails to acknowledge the complexity of both securitization processes and immigration policies; indeed it conflates, we believe, two misrepresentations.

On the one hand, it oversimplifies the multifaceted reality of immigration policies, in the sense that it does not seriously acknowledge the variety of interconnected immigration-related actions that constitute the EU's immigration policy (asylum, irregular immigration, etc.). It may be perfectly true, for example, that securitization occurs in the subfield of asylum but not in the subfield of highly skilled workers' immigration. It follows that one can only claim that 'immigration is securitized" if one shows that all aspects of the phenomenon have been securitized - otherwise the claim is an excessive generalization. The impressive quantity of more or less legally-binding documents that constitute the EU's immigration policy illustrates this multifaceted reality that should both discourage scholars to adopt too general conclusions on securitization, and encourage them to consider, as Boswell (2007) suggested, alternative framing moves. The studies evoked above tend either to provide undifferentiated statements on EU immigration policy at large or to over-

${ }^{1}$ We believe that this effort has led Huysmans to reach more balanced views than in his 2000 article. 
generalise a local conclusion of securitization from an immigration policy subfield to EU immigration policy broadly speaking.

On the other hand, the general question "has migration been securitized at the EU level?" misrepresents securitization dynamics themselves, by understanding securitization as a binary process. As it is asked, the question only seem to allow for "yes" or "no" as valid answers, which does not reflect the complexity of this social process. In line with Bourbeau (2011) ${ }^{2}$ and McInnes and Rushton (2011), and drawing on Williams' intuition that "securitization cannot be tied exclusively to extremity and emergency, but comprises a wider spectrum of intensification" (Williams, 2011: 218), we believe that securitization process and outcomes are best understood on a continuum. We claim that securitization is better understood as the result of practices and framing narratives whose securitizing intensity may be more or less strong. In particular, we illustrate the importance to study in a rigorous fashion the "semantic regularity" (Balzacq, 2011b: 11) of the discourses that play a role in securitization moves, rather than to try to find out a single, isolated speech-act which is accepted or refused by the public. The assessment of securitization (and securitization moves) has to be gradual and not binary.

In the following section, we detail how our method overcomes these two - methodological and theoretical - shortcomings, and therefore how its application to the case of EU immigration policy may help solving the lack of consensus on the question of the securitization of this policy field.

\section{Diagnosing securitization: A method}

In a nutshell, our method consists in the statistical treatment of a fully automated (computer-operated) language analysis of key documents in the field of EU immigration policy. The aim is to measure the saliency within these texts of the security "semantic regularity". Quantitative measurement stands out as a perfect complement to previous qualitative studies of EU migration policy and as a useful tool for ST in general. ${ }^{3}$ Before exposing how we reach our aim, it is worth explaining the exact ambition of the method is within the theoretical framework of ST.

\section{a) Measuring securitization: The theory beyond the method}

Securitization theory has developed in two steps. First, and due to the influence of Austinian and Searlian philosophies of language, initial formulations of ST (e.g. Waever, 1995) insisted on the importance of "speech acts". Under this perspective, a securitizing move is an attempt made by a political actor to rhetorically convince the public that a social issue belongs to the realm of security problems and thereby calls for exception politics. As Stritzel (2007) recalled, there are therefore three key components in a securitization process: a securitizing actor, the securitizing move itself, and an audience. A securitizing move thus ought to be understood as a performative linguistic action: under particular circumstances, the very utterance of specific words provokes tangible results. For a securitizing speech act to succeed, Buzan, Waever and De Wilde (1998) identified two minimal conditions of circumstance: the actor should have a certain level of legitimacy, and the speech has to make use of clearly security-laden words.

Then, in the 2000s, this stimulating framework has repeatedly been refined by the addition of sociologically-inspired elements that allowed for a more sophisticated depiction of securitization dynamics, until then solely analysed through a philosophical perspective. This sociological turn, crystallized in Balzacq's 2011 edited book Securitization Theory, mostly focused on the social conditions under which an audience accepts the move, making securitization effective. Thereby, the

\footnotetext{
${ }^{2}$ Even if Bourbeau's analysis ultimately relies on binary indicators.

${ }^{3}$ We do not claim that quantitative methods have the monopoly of rigor; our quantitative method should not be understood in opposition with qualitative reasoning, but rather as an attempt to correct the methodological imbalance in ST; methodological diversity is a sane practice that helps reaching conclusions from different angles.
} 
study of linguistic acts has been complemented by that of social practices. Boswell concluded that securitization may occur at both the levels of political discourse - which corresponds to the system of politics - and of practice - which corresponds to the system of administration, that is, "the activities of those parts of the administration involved in the elaboration and implementation of collectively binding decisions" (Boswell, 2007: 592).

Securitization processes therefore possess a multifaceted reality that makes them very complex to trace and assess; at least they call for a diversity of methods, each calibrated to the aspect of practice or discourse that is considered. Accordingly, our method does not have the ambition to provide a definitive answer to the question of the securitization of migration at the EU level; rather, its aim is to contribute building a robust answer to this question by focusing on one particular aspect of the securitization process. Even after its sociological turn, ST gives language in general and framing in particular a primordial place. We aim to assess the extent to which discourse in a given field (here, immigration at the EU level) is characterized by a security "semantic regularity"; in other words, our method seeks to measure the presence of words, verbs and concepts with a high security connotation within carefully selected written or spoken accounts of the issue at stake. This project builds on Ciuta's (2009) warning that securitizing moves rarely proceed through the clear-cut, direct and repeated depiction of the issue as a threat or as a security issue, but rather proceed through complex linguistic framings made of an entire conceptual ensemble. By providing scholars with a method which is apt at measuring the intensity of such a security conceptual system within texts, we hope to make a significant step towards less evaluative procedures in ST (and thereby towards a less contestable position on the securitization of immigration at the EU level), in line with a continuum view of securitization moves. Successfully studying conceptual systems decisively contributes to reveal the construction of meaning which is so crucial in securitization moves. Moreover, by considering large security-related linguistic repertoires, we also want to undermine the artificial separation of discourse on the one hand and practices in the other hand, showing instead that a specific language use can be understood as a more or less conscious practice. In line with Wittgenstein's Philosophical Investigations, we analyse language use as practice (Wittgenstein, 1953). Let us insist, at this point, that our method is not tailored to reveal any sort of causal origin of securitization moves or to evaluate the changes in opinion eventually provoked by these moves; rather, our ambition is to provide a robust tool calibrated to the essential linguistic aspect of securitizing moves.

Given this precision on the scope and ambition of our method, we can now expose the two interconnected elements of this method that respond to the aforementioned shortcomings: first, we need to get sampling and comparison principles right, and second, we need to expose how the sample is analysed, in other words to determine which tool is used to produce meaningful results, and how it does so.

\section{b) Measuring securitization: The advantages of a robust data sampling}

Measuring the intensity of a security framing has to rest on solid and transparent sampling choices. Our sampling method obeys two principles.

The first principle is that sampling should reflect the various components of the policy. Even when understood strictly as the political choice (and implementation of this choice) of who is (not) allowed to enter and stay in a given territory (Rüegger 2007: 102), immigration policy is inevitably made up of multiple components that intermingle but should not be confused. One cannot extrapolate from the analysis of one or several texts or practices that address a single aspect of immigration policy (e.g. asylum, or irregular immigration). Sampling should therefore cover the full spectrum of the EU's action in the field of immigration, and aptly reflect each one of the four subfields regulated by the EU: asylum, external borders, illegal immigration, and legal immigration (this is the classification of immigration-related fields which is presented by the EU website and therefore reflected in official documents. By taking this categorisation at face value, we do not seek to endorse its pertinence or objectivity; rather, we acknowledge the precise way the EU understands 
and acts upon immigration). ${ }^{4}$ What's more, and as exposed below, our approach necessarily has to be comparative if we want our scale be meaningful. Our method could in this regard be useful for the project of comparing security framing in various policy (sub)fields, or to contrast the securitization attempts of a given issue by various actors (e.g. political parties, states) or across time. For our endeavour, it is more pertinent to compare and contrast the security language in the various subfields of immigration policy at a given moment than to try and establish a cross-periods comparison, even if this latter option seems to be more adequate with the idea of securitization as a process. This last option does not yet make much sense in the context of EU immigration policy, since the various elements of this policy (understood as a fully communitarized policy) are too recent to be put under diachronic analysis. Consequently, if we want to avoid over-generalisation, we ought to avoid a diachronic perspective which is only consistent with situations where official classifications are permanent in time and have been implemented through several successive legal acts, which is not yet fully the case at the EU level of immigration policy. Hence, our four samples reflect the four subfields of immigration listed above: we selected official documents on asylum (they make the "Asylum Sample", from now on "AS"), legal immigration ("LS"), illegal immigration ("IS"), and borders ("BS").

This enabled us to compare the respective levels of security narratives of the four samples. It did not, however, allow us to assess whether these scores are high or low. For that reason, we constituted two reference comparison samples so as to provide norms of comparison that help situate if the levels of securitizing narratives of the four samples are high or low. We first built a sample of EU texts exclusively dedicated to "hard" security issues ("Security Sample", from now on "SS"): ${ }^{5}$ we gathered all EU texts implementing the CFSP ${ }^{6}$ and the $\mathrm{ESDP}^{7}$ that are currently into force, plus those explicitly addressing anti-terrorism. We then operated a random selection within all EU legislation in order to constitute a sample which is supposed to have a "normal" - that is, statistically average - level of securitization ("Random Sample", from now on "RS"): we randomly picked ten dates between 1999 and today, and blindly downloaded all texts in the official EU journal on these dates, regardless of their thematic focus (these 113 texts were very diverse: some documents were related to internal trade, others were bilateral agreements with third countries, or regulations on medicines, etc.). Since no issue is, according to ST, essentially a security issue, all can potentially be securitized, hence our random sample is characterized by the average level of securitizing words in the EU context. ${ }^{8}$

Our second principle is that given the vast amount of texts and events that make the EU's immigration policy in these four dimensions, the ST researcher should stick to a defendable principle that guides his choice to consider or ignore this or that text or event. In other words, there has to be an openly defended rule for governing the eligibility of any given text or practice for a sample. In our case, because our focus is language, we have chosen to implement a content analysis of the documents that are currently in force in each of the four dimensions of the EU's action on immigration. For instance, we have gathered the various documents that currently officially implement the EU's action in the field of asylum, which has in turn several aspects: minimal conditions for the reception of asylum seekers, minimal standards for the return of irregular immigrants, etc. For each of these

\footnotetext{
${ }^{4}$ It may be argued that, strictly speaking, the EU immigration policy only encompasses legal immigration, and that asylum and external borders are distinct fields, with illegal immigration being a residual repressive policy concerned with those who do not comply with the rules organizing legal immigration, asylum and external borders. Such an approach would be misleading though, since all four fields are present in all major orientation documents, are dealt with by the same DG of the Commission, and are addressing together, in an interconnected way, the common task of organizing the movement of people towards the EU territory.

${ }^{5}$ We understand that for ST there is no such thing as an already-existing class of "hard security issues", since it is claimed that no issue essentially pertains to the realm of security. Although the contrary hypothesis may coherently be argued, our sampling does not need to engage with this debate: it encompasses the issues that the EU itself presents as belonging to the domain of "hard" security.

${ }^{6}$ Common Foreign and Security Policy.

${ }^{7}$ European Security and Defense Policy.

${ }^{8}$ Since this random sample inevitably contains security-related documents, it cannot be considered as expressing a normal politisation.
} 
aspects, there is logically only one single legislative document currently in force: for example the "Reception directive" (2003/9/EC), or the "Return directive" (2008/115/EC). We did not consider previous versions of these documents, nor did we take into account the numerous preparatory texts, as the idea is to measure security words as they currently (do not) prevail in EU immigration policy. Would the EU openly claim to have an action on a given side-aspect of immigration but without having yet a legally-binding text that tackles the issue (a directive or a regulation), we selected the non-legally binding text that expresses the most recent view of the EU in the field, usually a directive proposal. The list of the documents constituting our samples is available in Annex1. Our choice to select current legally binding acts stands for two reasons. First, these documents express the EU's action as it is actually carried out, since they are legally-binding texts (or are in the process of being so); second, they always contain a first section exposing the context and objectives of the legislative act. This is consistent with our conception of language as a practice and therefore makes the analysis of securitizing discourse useful for the study of securitizing practices.

As regards our task to remedy the two shortcomings displayed by ST studies of EU immigration policy, these clear sampling options possess two big advantages: they lead us away from evaluative procedures, and they acknowledge the multifaceted reality of EU immigration policy. As explained above, any attempt to diagnose securitization needs to take into account the various aspects of the policy/phenomenon under scrutiny, and to recognise that those aspects might have different securitization realities. Here, EU immigration policy is made up of several subfields, whose respective permeability to securitization dynamics might differ.

\section{c) Measuring securitization: The advantages of an efficient tool}

We suggest that an automated language analysis is a particularly fruitful tool for strengthening ST empirical studies. Our method is based on a tailored use of the LIWC software (Linguistic Inquiry and Word Count), ${ }^{9}$ a fully automated computer-based language analysis aimed at detecting linguistic regularities in written statements. Among others functionalities, the LIWC calculates the frequency, in any given text, of specific words and kinds of words (e.g. verbs, words with more than three syllables, etc.); it provides the ratio of these words and kinds of words out of the total amount of words of the statement.

The LIWC was initially designed as a support tool in psychological counselling, but has since then been used in different settings (e.g. Cohn, et al., 2004 on the psychological consequences of September 11 $11^{\text {th}}$; or Rude, Gortner and Pennebaker, 2004 on depression among students) because of both its flexibility and its robustness in measuring the emotional tone of texts (read Kahn, et al., 2007). This second quality of emotion detection is of no use here, but we take full advantage of the first one, as we easily altered the functioning of the software for the purpose of measuring the intensity of securitizing language within our samples. More precisely, one possibility given by the software is allow the user to modify or even create the set of preselected words, parts of words, or kinds of words whose occurrences have to be automatically counted within the given corpus of written texts; the software then calculates the proportion of these words over the full amount of words in the corpus. We created a "security" set (from now on "Security Lexicon" or "SL") whose aim is to provide the ratio of security-related words used in our samples. This lexicon is available in Annex2. Building on Ciuta's suggestion (see above), we take as an axiom that the more a political actor makes use of words taken out of this set, the more his narrative establishes a securitizing move. In other words, a high ratio of $S L /$ total words (from now on "Security Ratio") orients the scholar - together with other analyses, such as process-tracing - towards an overall diagnosis of securitization, whereas a low ratio reflects a low saliency of security words and therefore a lower probability of facing a securitizing move. To establish SL, we aggregated two reference glossaries exclusively dedicated to security issues: the UN glossary of terms and concepts in peace and conflict studies

9 Pennebaker, et al., 2007. 
and the final index of the Palgrave handbook in security studies. ${ }^{10}$ We operated several changes in the aggregated list, in order to suppress any ambiguity in the results provided by the software. First, we suppressed from these glossaries and indexes the names of scholars (e.g. "Mearsheimer", "Morgenthau") as they cannot be considered as words that could possibly participate in the securitization of an issue in front of a non-specialist audience - we left over, on the contrary, names of prominent political actors associated with widely known criminal acts (e.g. "Bin Laden", "Baader") and places clearly associated with well-known military intervention or high strategic military importance (e.g. "Vietnam", "Afghanistan"), as the sole evocation of these individuals and places may in theory suffice to securitize, via powerful metonymic effects. ${ }^{11}$ Second, we suppressed words that cannot be considered to produce, in themselves, securitizing effects (e.g. "society", "agency"). Third, we also erased concepts that have the status of basic-level categories ${ }^{12}$ in the immigration debate (e.g. "asylum", "immigration", "refugee"), since these categories are precisely those under analysis here and should therefore not be a priori considered to play a role in a specific framing (such as security). Finally, we merged terms whose lexical basis is identical in their minimal common group of letters (e.g. "threat*" encompasses "threat", "threatening", "threatens", etc.). ${ }^{13}$

Creating four immigration samples and two reference samples, and modifying the LIWC by creating a security lexicon allows us to disclose results that reflect the complexity of political reality as they mirror a continuum between a normal and a very high saliency of security language. We ran the LIWC for each text within each immigration-related sample (AS, BS, IS, SS) as well as for each control samples (RS, SS), and we computed the mean and the standard-error of the six samples. This provided, for each sample, a precise Security Ratio. As noted above, the ratio has no signification per se: it only makes sense in comparison with other scores. In order to make this comparison, we used an adapted version of Student's t-test (one-tailed Welch's t-test) to detect significant differences between the Security Ratios of all samples. We used Welch's t-test because it is a generalisation of Student's t-test intended for confronting two samples having possibly unequal size and variances - this choice is not only pertinent as regards the characteristics of our samples, it also reflects our will to provide scholars with a statistical tool which is directly implementable to the widest possible array of case-studies. For two sample of size $N_{1}$ and $N_{2}$, means $\bar{X}_{1}$ and $\bar{X}_{2}$, and unbiased variance $s_{1}^{2}$ and $s_{2}^{2}$, the Welch's t-statistic is given by: $t=\frac{\overline{X_{1}}-\overline{X_{2}}}{\sqrt{\frac{s_{1}^{2}}{N_{1}}+\frac{s_{2}^{2}}{N_{2}}}}$, with $v=\frac{\left(s_{1}^{2} / N_{1}+s_{2}^{2} / N_{2}\right)^{2}}{\frac{\left(s_{1}^{2} / N_{1}\right)^{2}}{N_{1}-1}+\frac{\left(s_{2}^{2} / N_{2}\right)^{2}}{N_{2}-1}}$ degrees of freedom.

Using this LIWC tool and treating its raw results with the Welch's t-test has two decisive advantages in our project of addressing the shortcomings of ST studies of EU immigration policy. First, the advantage of an automated analysis stands in the fact that it does not suffer from

\footnotetext{
10 This choice is of course one possibility among others. We believe, though, that it is perfectly justifiable and pertinent given both the specialized focus of the glossaries and the broadly comparable content of the glossaries of the various handbooks of security studies.

${ }^{11}$ Read Krebs and Lobasz (2007) on the Bush administration's recurrent comparison of Saddam Hussein with Hitler, which participated in establishing Iraq as an urgent security problem calling for a non-diplomatic solution.

${ }^{12}$ Literature in cognitive science has acknowledged, since the work of Rosch and Mervis (1975), that everyday language heavily relies on a small amount of "basic-level concepts", that is, words whose contents are not too specific or too general. For any given discussion on a precise issue, basic-level concepts necessarily emerge and become highly recurrent, thereby structuring discussion. Any policy is based on a limited number of basiclevel categories (Baele, 2013).

13 This is a technical requirement of the LIWC.
} 
subjectively oriented, or at least partial, reading and interpretation of texts. ${ }^{14}$ This sort of tool should be distinguished from classic qualitative linguistic analysis software (such as Nvivo), wherein the user constructs the categories of interpretation in the course of his/her reading of the texts. In contrast with this logic, in the present case a fully automated process takes place, wherein the categories of analysis are set up in advance (before the scholar has even read the documents), ${ }^{15} \mathrm{a}$ method that could be compared with a medical diagnosis where the symptoms are agreed upon prior to facing the empirical case (Roberts, 1997). In a way, our method resembles that implemented in Laver, Benoit and Garry's study of political preferences (2003), or in Danielson and Lasorsa's analysis (1997) of the evolution of contents in the New-York Times and Los Angeles Times from 1880 to $1980 .{ }^{16}$ Hence, our method is better classified as "content analysis" than as "discourse analysis" in Balzacq's typology of potentially available methods in ST, since content analysis "emphasizes the measurability of variables or counting and coding [...using...] essentially quantitative methodologies" (Balzacq, 2011c: 51).

Second, our method provides a measure of the intensity of security narratives within each of the samples corresponding to a particular subfield of immigration policy, and by doing so helps overcoming simplistic binary, yes/no answers to the question of the securitization of immigration policy at the EU level, in line with Williams' call to consider securitization as a continuum. Our quantitative approach is apt at providing such a "fuzzy" evaluation.

\section{Diagnosing the securitization of immigration at the EU level: A step forward}

We are now in an ideal position to make a substantial step towards answering the question of the securitization of migration at EU level. Our method discloses two prominent results: on the one hand security language appears to reach an abnormally high level, which tends to accredit the securitization thesis. On the other hand, however, the picture is not at all uniform, in the sense that there are significant differences between the levels of security language respectively obtained by the four immigration-related samples, which tends to accredit the point of view according to which it is simplistic to claim that immigration has been securitized at the EU level.

\section{a) Security language is abnormally high}

When put side by side in Figure1 below, it is easily noticeable that all samples score in between the random sample of European legislation and the sample of texts related to hard security issues, which means that all present a statistically abnormally high presence of security words. Figure1, built after Table1, clearly shows that all four samples of immigration-related texts, even LS, contain more securitizing words than the average of the whole EU legislation; however, they still obtain much less than the policy documents specifically dealing with security threats.

\footnotetext{
${ }^{14}$ Hart (2001) offers a metaphor to illustrate the need to use fully automated linguistic analysis tools in addition to qualitative approaches: using qualitative methods is like sightseeing a city with a car whereas fully automated quantitative devices are comparable to watching this city from a helicopter. Both points of view offer insights on the city, but none of them should be neglected since the city is only finely understood once the two perspectives are provided.

${ }^{15}$ In fact, it is not even necessary for the analyst to read the documents ran by the software. He/she only needs to be sure that the documents under scrutiny are pertinent for its enquiry. Sampling is therefore a crucial aspect of the analysis.

16 Among others, Danielson and Lasorsa measured the dramatic increase in quantification words, of "expert" or "official" vocabulary, and conversely the steady decrease in the frequency of "religious" words and concepts related to the agriculture.
} 


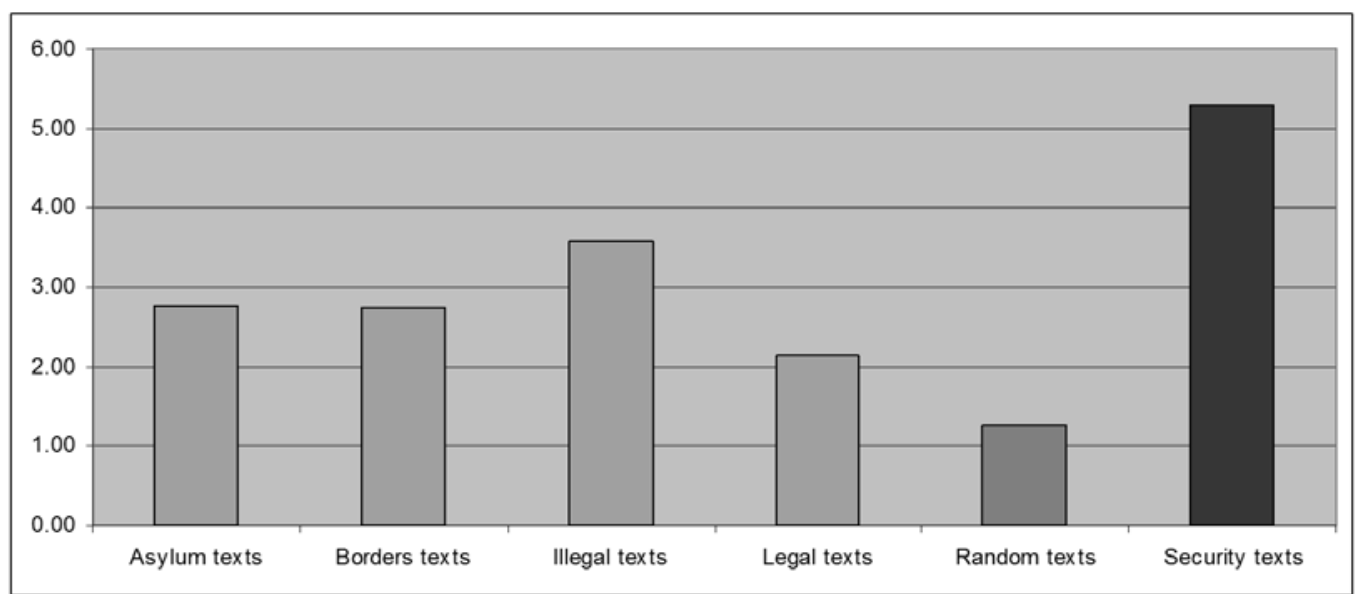

Figure1: Perspective on mean results for the 4 migration samples, the random sample, and the security sample.

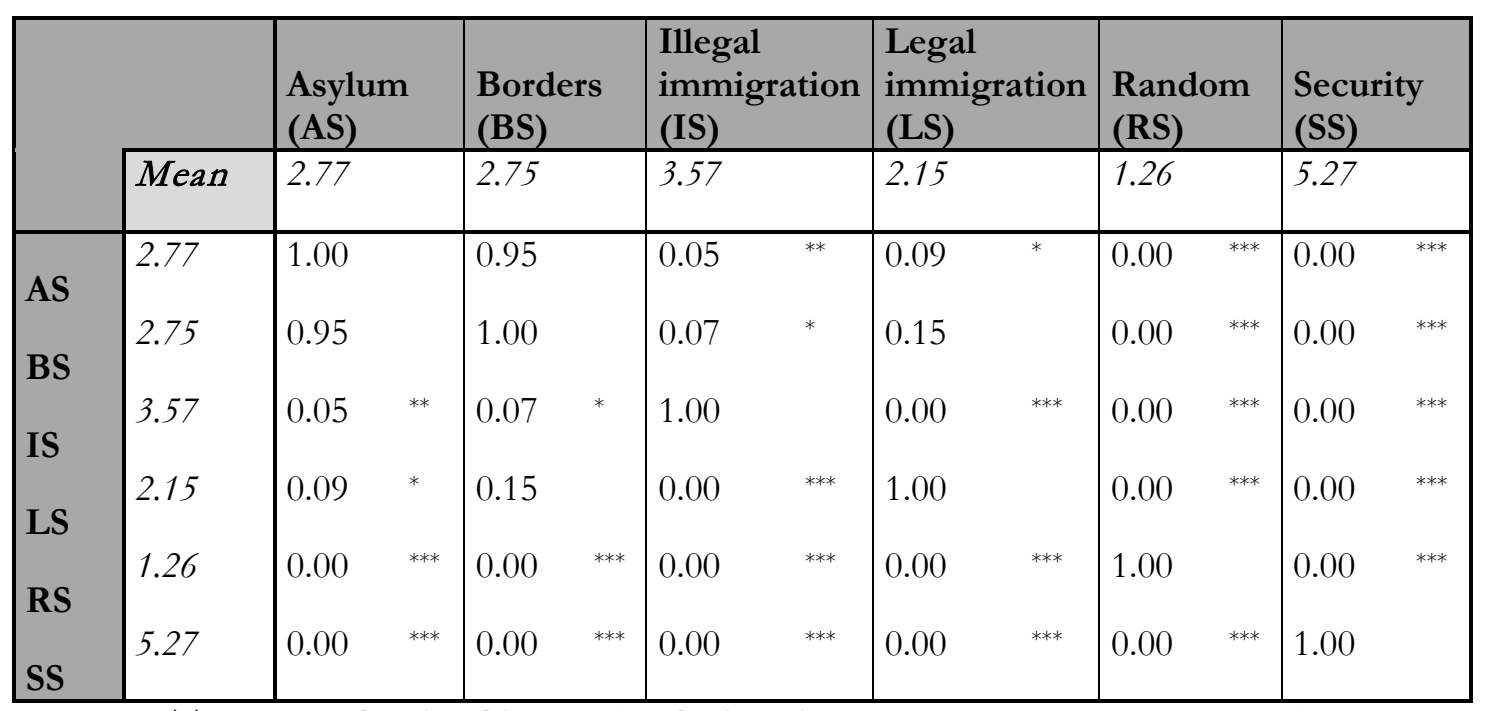

Table1: $p$-value of Welch t-tests (Levels of significance: $10 \%=*, 5 \%=* *, 1 \%=* * *$ ).

This result exemplifies the merit of a fuzzy diagnosis of securitization. With a binary conception of securitization, one could here be comforted in the view according to which immigration had entered the realm of security problems; we see, however, that such a statement is simplistic up to the point of being incorrect: none of the samples obtain a security ratio close to the score of SS, far from it. Of course, no-one would claim that the level of SS is needed to accredit the securitization thesis, but we are forced to observe that immigration is not fully treated like a security issue. Conversely, one cannot claim that immigration is not securitized at the EU level, since the very fact that all immigration-related samples score well above RS constitutes a non-negligible sign that such a process exists.

Our continuum, fuzzy approach allows us not only to adopt a balanced view on the securitization of immigration, but also to precisely calculate and represent this balance. In our case, AS, BS, LS, and IS obtain Security Ratios ranging between 2.15 and 3.57, which makes them significantly different, statistically speaking, than both RS and SS, as the p-values show. More remarkably, looking behind mean scores (Security Ratios), we notice that not a single text on immigration scores lower than the Security Ratio of RS, and at the other end of the spectrum not a single piece of our corpus obtains a higher score than the Security Ratio of SS. These observations illustrate the insufficiency of the binary conception too often endorsed in ST: whilst security concerns for sure permeate from all immigration-related samples, immigration is far from being fully framed as a security issue. 


\section{b) Security language is not uniformly distributed}

This picture of an abnormally high yet intermediate intensity of the security repertoire in the texts addressing immigration at the EU level should nonetheless be contrasted. This saliency indeed varies considerably depending on which subfield is considered, as each sample obtains a different security ratio. Among our four samples, IS is the most tainted by security words, and LS has the lowest score. Texts on asylum (AS) and those on borders (BS) obtain almost the same ratio; interestingly, AS scores slightly higher than BS. These results are summarized in Table1, which provides not only samples means but also the p-values of the Welch t-test for each pair of samples, hence offering a comparative perspective.

Texts on illegal migration score significantly higher than all three other groups of texts. The sample of texts on illegal migration indeed presents a proportion of terms related to security which is no less than $40 \%$ higher than what is observed in the texts on legal movements, $22 \%$ higher than in the legislation on political asylum, and 23\% higher than in the texts on borders. On the contrary, texts on legal migrations score significantly lower than the texts on political asylum, borders and illegal immigration, and should therefore be analytically set apart. The proportion of words which are both in the security lexicon and in the sample of texts on legal migrations is $29 \%$ lower than the proportion of security terms found in texts related to asylum, $28 \%$ lower than the proportion found in the sample of text related to borders, and $66 \%$ lower than the proportion found in texts dealing with illegal immigration issues. It is worth noting that the score of the Asylum Sample is possibly overestimated, boosted in an artificial way by the recurrent use of words from the security lexicon in completely other, almost de-securitizing way. For example, the Qualification directive concerns any "person who is located outside of his/her country of origin and who is unwilling or unable to return to it owing to a fear of being persecuted" - a sentence wherein the terms "fear" and "persecution" are present, but certainly not as parts of a securitizing move. Such ambivalence cannot be treated by our fully automated method and should be taken as one of its shortcomings. We do not believe, though, that this limitation undermines the coherence of the overall picture of securitizing narratives in EU immigration policy, nor do we estimate that it precludes future implementations of this method in other fields.

Taken together, these results contribute to offer a contrasted picture of the securitization of immigration at the EU level. They reflect a very specific way to understand and act upon immigration, which differs from immigration policies implemented in Europe in the past and raises two important challenges. The first one relates to illegal immigration. One can rightfully argue that action on illegal immigration heavily relies on a security repertoire, much more than other immigration subfield, even if one cannot claim that this issue is completely framed as a security issue, since the difference with SS is huge. This diagnosis calls for further critical or ethical enquiry, because quite a series of very different situations are conglomerated within this label of "illegal" (also called "irregular") immigration: tourist visa overstayers, rebutted asylum-seekers, smuggled economic entrepreneurs, or victims of human trafficking. The securitization of the whole of this heteroclite ensemble reflects the problem with creating (as the EU does) a category of "illegals" instead of working, as in any other legal field, with as many categories as there are reprehensible behaviours.

The second challenge relates to legal immigration. At the low end of the spectrum, legal immigration seems to be the least securitized immigration subfield, by quite a margin, which reflects the Commission's will to offer easy access to the EU territory for those who are eligible for the various schemes: highly skilled workers, intra-corporate transferees, scientists, and family members (there is two common criteria for appurtenance to these categories: the candidate has to possess a working contract with a high salary, and has to prove that he will bear no cost on the social security system). The EU hence allows net contributors to its economy to legally immigrate, but - contrarily to the US for example - provides no legal route for all other categories, a logic similar to that of hiring policies of private sector firms. We suggest the hypothesis, open to further research, that a managerial framing - measured by a new, specific LIWC lexicon - would score very high in this subfield and very low in other ones. To help make this contestable "hiring" policy acceptable, the 
category of "legal immigrant" is not much addressed though a security repertoire, whilst other categories experience higher degrees of securitization. The higher level of securitization of illegal immigration acts as a warning against anyone who intends to challenge, in any way, this legal framework, and as a way to insist on the objectivity and hence legitimacy of the existing legal routes.

In sum, while our method somehow supports the hypothesis of securitization, fuzzy evidence shows that the saliency of the security framing in the European legislation is never sky high and widely varies across subfields. This variation sustains the acceptability of the very particular "hiring" logic to which the EU immigration policy seems to obey.

\section{Conclusions}

Our paper offered a transparent and rigorous evaluation of the intensity of the security framing in EU immigration policy, with the aim of contributing to establish a more accurate and less contestable verdict of securitization in this field. A quantitative method was designed on the basis of a fully automated linguistic analysis software (LIWC) so as to assist ST researchers overcoming too general and binary claims of securitization, providing them instead with the operational capacity to offer nuanced fuzzy assessments of the linguistic aspect of securitization moves.

In the course of designing this method, choices have been made, as regards sampling or the constitution of lexicons for example. Whilst any one of these choices can of course individually be debated, as it is always the case in quantitative studies, we nonetheless believe that they have the twofold merit of being transparently exposed and of being more practically feasible and defendable than alternatives. Together, our choices built a coherent picture of EU immigration policy that helps establishing an overall diagnosis of securitization. We showed that the EU immigration policy has an abnormally high - though not top-scale - presence of security language, but we also revealed the uneven intensity of this framing when the various subfields of immigration are distinguished. Such an approach is far from being incompatible with the critical dimension that characterises ST in general and ST empirical studies of EU immigration policy in particular, in that it reveals contrasted policy realities and thereby unfolds clearer, more specific paths for alternatives.

As explained and justified, our method neglects one important tenet of ST: the audience, who either endorses, ignores or contests securitizing narratives and practices. Given the importance of the audience in the most up-to-date versions of ST, we could have pushed our analysis further, for example by considering Europe-wide polls, adopting a dual strategy of measuring securitization in political narratives on the one hand, and measuring the public adherence to this move on the other hand. However, there are no recent Eurobarometer at hand that could provide sufficiently rich and meaningful statistics directly on the matter, and even if this data existed, it would not necessarily reflect the success or failure of the securitizing move of EU actors.

One of the key merits of this method is that it can easily be used by ST scholars working on other issues than EU immigration policy. For example, one can imagine a comparative analysis that would contrast the respective levels of security framing obtained by EU and US policies in a given field (e.g. immigration, ecology, or education), or a diachronic research that would aim at revealing the variation, within an area but across time, of the security ratios of a given field (e.g. immigration, HIV/AIDS, or prostitution). As "securitization denotes one particular way of framing migration issues" (Boswell, 2007: 592), this method could also be used in a broader attempt to gauge the saliency of security narratives in comparison with other framings. To be sure, the lexical fields of management and of human rights are also present, together with that of security, in the documents that implement EU immigration policy. Further research could provide an evaluation of the various framings at stake in the different subfields of EU immigration policy, exposing in greater depth its coherence with the neoliberal worldview, an enterprise which clearly stands well beyond the scope of the present paper. 


\section{References}

Baele, S. (2013) Critique of immigration categories: An analysis of the European Commission's immigration policy, $\mathrm{PhD}$ thesis, Namur: University of Namur.

Balzacq, T. (2008) "The policy tools of securitization: Information exchange, EU foreign and interior policies", Journal of Common Market Studies, vol.46, n¹, pp.75-100.

Balzacq, T. (2011a) "Preface". In Balzacq, T., ed. Securitization theory. How security problems emerge and dissolve, New York: Routledge PRIO.

Balzacq, T. (2011b) "A theory of securitization. Origins, core assumptions, and variants". In Balzacq, T., ed. Securitization theory. How security problems emerge and dissolve, New York: Routledge PRIO.

Balzacq, T. (2011c) "Enquiries into methods. A new framework for securitization analysis". In Balzacq, T., ed. Securitization theory. How security problems emerge and dissolve, New York: Routledge PRIO.

Balzacq, T., Leonard, S. (2011) Methodology and progress in securitization studies, Mimeo, University of Namur.

Bigo, D. (2002) "Security and immigration: Towards a critique of the governmentality of unease", Alternatives, vol.27, $\mathrm{n}^{\circ} 1$, pp.63-92.

Boswell, C. (2007) "Migration control in Europe after 9/11: Explaining the absence of securitization", Journal of Common Market Studies, vol.45, n³, pp.589-610.

Bourbeau, P. (2011) The securitization of migration. A study of movement and order, New York: Routledge.

Buonfino, A. (2004) "Between unity and plurality: The politicization and securitization of the discourse of immigration in Europe", New Political Science, vol.26 n¹, pp.23-49.

Buzan, B., Waever, O., de Wilde, J. (1998) Security: A new framework for analysis, Boulder: Lynne Rienner.

Castles, S., Miller, M. (2009) The age of migration. Fourth edition. London: Palgrave.

Ciuta, F. (2009) "Security and the problem of context: A hermeneutical critique of securitization theory", Review of International Studies, vol.35, n², pp.301-326.

Cohn, M., et al. (2004) "Linguistic markers of psychological change surrounding September 11, 2001”, Psychological Science, n¹5, pp.687-93.

Danielson, W., Lasorsa, D. (1997) "Perceptions of social change: 100 years of front-page content in The New-York Times and the Los Angeles Times". In Roberts C., ed. Text analysis for the social sciences. Methods for drawing statistical inferences from texts and transcripts, Mahwah: Lawrence Erlbaum.

Dover, R. (2008) "Towards a common EU immigration policy: A securitization too far", European Integration, vol.30, $\mathrm{n}^{\circ} 1$, pp.113-130.

Hart, R. (2001) "Redeveloping DICTION: Theoretical considerations". In West, M., ed. Theory, method and practice in computer content analysis, New-York: Ablex.

Huysmans, J. (2000) "The European Union and the securitization of migration", Journal of Common Market Studies, vol.38, $\mathrm{n}^{\circ} 5$, pp.751-77.

Huysmans, J. (2006) The Politics of Insecurity: Fear, Migration and Asylum in the EU, London: Routledge.

Huysmans, J. (2008) "Politics of exception and unease: Immigration, asylum and terrorism in parliamentary debates in the UK", Political Studies, vol.56, $\mathrm{n}^{\circ} 4$, pp.766-788.

Ibrahim, M. (2005): “The securitization of migration: A racial discourse", International Migration, vol.43, n5, pp.163-187.

Kahn, J., et al. (2007) "Measuring emotional expression with the Linguistic Inquiry and Word Count", American Journal of Psychology, vol.120, n² 2 , pp.263-286.

Karyotis, G. (2007) "European migration policy in the aftermath of September 11. The securitymigration nexus", Innovation, vol.20, n¹, pp.1-17.

Karyotis, G., Patrikios, S. (2010) "Religion, securitization and anti-immigration attitudes: The case of Greece”, Journal of Peace Research, vol.47, n¹, pp.43-57.

Krebs, R., Lobasz, J. (2007) "Fixing the meaning of 9/11. Hegemony, coercion, and the road to war in Iraq", Security Studies, vol.16, n³, pp.409-451. 
Laver, M., Benoit, K., Garry, J. (2003) "Extracting policy positions from political texts using words as data", American Political Science Review, vol.97, n², pp.311-331.

Neal, A. (2009) "Securitization and risk at the EU border: the origins of Frontex", Journal of Common Market Studies, vol.47, n², pp.333-356.

McDonald, M. (2008) "Securitization and the construction of security", European Journal of International Relations, vol.14, $\mathrm{n}^{\circ} 4$, pp.563-587.

McInness, C., Rushton, S. (2011) "HIV/AIDS and securitization theory", European Journal of International Relations, vol.19, n¹, pp.115-138.

Morse, J., et al. (2002) "Verification strategies for establishing reliability and validity in qualitative research", International Journal of Qualitative Methods, vol.1, n², pp.13-22.

Pennebaker, J., et al. (2007) "The development and psychometric properties of LIWC 2007", Mimeo, University of Texas at Austin.

Rosch, E., Mervis, C. (1975) "Family resemblances: studies in the internal structure of concepts", Cognitive Psychology, vol.7, pp.573-605.

Roberts C (1997): "Introduction". In Roberts, C., ed. Text analysis for the social sciences. Methods for drawing statistical inferences from texts and transcripts, Mahwah: Lawrence Erlbaum.

Rude, S., Gortner, E., Pennebaker, J. (2004) "Language use of depressed and depression-vulnerable college students", Cognition \& Emotion, n¹8, pp.1121-1133.

Rüegger, M. (2007): "Libéralisme, immigration et culture", Raisons Politiques, vol.26, n², pp.101-123.

Salter, M., Mutlu, C. (2012) Research methods in critical security studies, London: Routledge.

Sasse, G. (2005) "Securitization or securing rights? Exploring the conceptual foundations of policies towards minorities and migrants in Europe", Journal of Common Market Studies, vol.43, n 4 , pp.673-693.

Slingeneyer, T. (2008) "Rendre compte de la libération conditionnelle en Belgique: Prescriptions juridiques et usages du chiffre", Recherches Sociologiques et Anthropologiques, vol.32, n², pp.103-119.

Stritzel, H. (2007) "Towards a theory of securitization: Copenhagen and beyond", European Journal of International Relations, vol.13, n³, pp.357-383.

Van Munster, R. (2009) Securitizing immigration: The politics of risk in the EU, New York: Palgrave Macmillan.

Vultee, F. (2011) "Securitization as a media frame. What happens when the media 'speak security"' In Balzacq T., ed. Securitization theory. How security problems emerge and dissolve, New York: Routledge PRIO.

Waever O. (1995) "Securitization and desecuritization". In Lipschultz R., ed. On security, New York: Columbia University Press.

Watson, S. (2012) "Framing the Copenhagen School: Integrating the literature on threat construction", Millennium - Journal of International Studies, vol.40, n² 2, pp.279-301.

Williams, M. (2011) "The continuing evolution of securitization theory". In Balzacq, T., ed. Securitization theory. How security problems emerge and dissolve, New York: Routledge PRIO.

Wittgenstein, L. (1953) Philosophische Untersuchungen - Philosophical Investigations, London: Blackwell. 